\title{
Expression of epidermal growth factor receptor in squamous cell carcinomas of the anal canal is independent of gene amplification
}

\author{
Gustavo Alvarez ${ }^{1}$, Arie Perry ${ }^{1}$, Benjamin R Tan² and Hanlin L Wang ${ }^{1}$ \\ ${ }^{1}$ Lauren V Ackerman Laboratory of Surgical Pathology, Department of Pathology and Immunology, \\ Washington University School of Medicine, St Louis, MO, USA and ${ }^{2}$ Department of Internal Medicine/ \\ Medical Oncology, Washington University School of Medicine, St Louis, MO, USA
}

\begin{abstract}
Immunohistochemical detection of expression of the epidermal growth factor receptor (EGFR) has been utilized to identify eligible patients with solid malignant tumors, including colorectal adenocarcinoma, for monoclonal antibody therapy (eg, cetuximab). The EGFR status in squamous cell carcinoma of the anal canal, an uncommon malignancy traditionally treated with chemoradiation, has not been well investigated. In this study, 38 primary squamous cell carcinomas of the anal canal were immunohistochemically examined for EGFR expression and analyzed by fluorescence in situ hybridization (FISH) for EGFR gene copy numbers. The results showed a variable degree of EGFR expression in 21 (55\%) tumors, among which 13 (62\%) cases exhibited a $2+$ to 3 + staining pattern according to the Dako EGFR phamDx interpretation guide. There were no significant differences among tumors stratified by stage, degree of keratinization, or tissue block storage times. FISH analysis showed that none of the 34 cases with interpretable results had EGFR gene amplification. Increased gene copy numbers due to polysomy 7 were seen in seven of $18(39 \%)$ cases that expressed EGFR protein and four of $16(25 \%)$ cases that did not $(P=0.3876)$. Ten $(56 \%)$ tumors with positive EGFR staining showed a balanced disomy 7 pattern and one case with monosomy 7 exhibited strong EGFR expression (3+). These results demonstrate that EGFR is overexpressed in more than one-half of the squamous cell carcinomas of the anal canal through mechanisms other than gene amplification. These observations may have important therapeutic implications since EGFR-based targeted therapies have shown promise for other malignant neoplasms.
\end{abstract}

Modern Pathology (2006) 19, 942-949. doi:10.1038/modpathol.3800608; published online 28 April 2006

Keywords: EGFR; squamous cell carcinoma; anal canal; gene amplification; immunohistochemistry; fluorescence in situ hybridization

The epidermal growth factor receptor (EGFR; also known as erbB1) is a $170-\mathrm{kDa}$ transmembrane tyrosine kinase whose main ligands are epidermal growth factor (EGF) and transforming growth factor$\alpha(\mathrm{TGF}-\alpha)$. It is a member of the tyrosine kinase receptor family that also includes HER2 (erbB2), erbB3, and erbB4. ${ }^{1}$ Studies have shown that EGFR is expressed in many types of normal tissue and overexpressed in common epithelial neoplasms

Correspondence: Dr HL Wang, MD, PhD, Lauren V Ackerman Laboratory of Surgical Pathology, Department of Pathology and Immunology, Campus Box 8118, Washington University School of Medicine, 660 South Euclid Avenue, St Louis, MO 63110-1093, USA.

E-mail: hwang@path.wustl.edu

Received 7 February 2006; accepted 13 March 2006; published online 28 April 2006 such as carcinomas of the colorectum, ${ }^{2-4}$ stomach, ${ }^{4,5}$ esophagus, ${ }^{6}$ lung, ${ }^{7,8}$ pancreas, ${ }^{9}$ breast, ${ }^{10}$ bladder, ${ }^{11}$ kidney $^{12}$ and head and neck. ${ }^{13}$ It is believed that EGFR contributes to tumor development and progression through autocrine stimulation of cell proliferation, ${ }^{14}$ and that tumors with increased EGFR expression levels generally bear a poorer prognosis. ${ }^{15,16}$

Given its critical role in regulating proliferation and survival of tumor cells, EGFR has been the subject of intensive investigation for targeted therapies. ${ }^{17}$ Among the various rationally designed target-based therapeutics, monoclonal antibodies and small-molecule tyrosine kinase inhibitors have become attractive anticancer modalities owing to their high specificity for tumor cells. ${ }^{18,19}$ Recently, the US Food and Drug Administration (FDA) 
approved a chimeric IgG $_{1}$ monoclonal antibody, cetuximab (Erbitux), as an EGFR-targeting drug for the treatment of advanced colorectal cancer, and erlotinib (Tarcera) for the treatment of lung and pancreatic cancers. Preclinical studies have shown that cetuximab specifically binds to EGFR with an affinity higher than that for either EGF or TGF- $\alpha$, thus blocking ligand-induced EGFR tyrosine phosphorylation and subsequent activation of the downstream cascade of signal transduction. ${ }^{15,20}$ Randomized clinical trials have demonstrated that cetuximab not only possesses effective antitumor activity as a single agent, but also enhances the effects of radiation and various chemotherapy regimens. ${ }^{15,17,21-23}$ In this regard, immunohistochemical detection of EGFR expression may be used to identify eligible patients, although the degree of EGFR expression does not appear to correlate with the likelihood of tumor regression in response to cetuximab treatment. ${ }^{24-26}$

Squamous cell carcinoma of the anal canal is an uncommon malignancy but its incidence has increased considerably in recent years among women and among men younger than 45 years. ${ }^{27,28}$ Population-based case-control studies have linked this increase to changes in sexual behavior, ${ }^{27}$ with a strong etiopathogenetic association with human papillomavirus infection. ${ }^{29,30}$ As the patients with squamous cell carcinoma of the anal canal are traditionally managed with combined chemoradiation therapy, rather than by surgical means alone, ${ }^{31}$ we investigated EGFR expression in these tumors to determine whether the patients might rationally benefit from targeted therapies, such as cetuximab.

\section{Materials and methods}

\section{Case Selection}

A total of 38 squamous cell carcinomas of the anal canal were retrieved from the surgical pathology archives at Washington University Barnes-Jewish Hospital between 1989 and 2003. These included 31 biopsies and seven resection specimens. Hematoxylin- and eosin-stained slides were re-examined to confirm the original diagnosis. Clinical data were also reviewed to make certain that all the tumors included in the study were indeed anal canal primaries. Tumors arising from perianal skin and cases with a known history of squamous cell carcinoma in other anatomic locations, for example, uterine cervix, were excluded. This study was approved by the Human Studies Committee of Washington University Medical Center.

\section{Immunohistochemistry and Data Analysis}

Immunohistochemical staining was performed on 4- $\mu \mathrm{m}$ formalin-fixed, paraffin-embedded tissue sections employing the LSAB Plus system (Dako Corp.,
Carpinteria, CA, USA) and the ABC kit (Vector Laboratories, Burlingame, CA, USA) following the manufacturers' instructions. Briefly, deparaffinized sections were first treated with $3 \% \mathrm{H}_{2} \mathrm{O}_{2}$ for $15 \mathrm{~min}$ to inhibit endogenous peroxidase activity and then subjected to antigen retrieval for $5 \mathrm{~min}$ at $37^{\circ} \mathrm{C}$ with a bacterial protease extracted from Streptomyces griseus (EC3.4.24.31; Sigma Chemical Co., St Louis, $\mathrm{MO}$, USA) at a concentration of $0.75 \mathrm{mg} / \mathrm{ml}(5.6 \mathrm{U} /$ mg) in phosphate-buffered saline ( $\mathrm{pH}$ 7.6). After incubation with blocking serum for $20 \mathrm{~min}$, sections were incubated with a mouse monoclonal antibody $\left(\operatorname{IgG}_{1}\right)$ against EGFR (clone 31G7) obtained from Zymed Laboratories Inc. (South San Francisco, CA, USA) for $1 \mathrm{~h}$ at room temperature with an antibody dilution of 1:80. After further incubation with biotinylated link antibodies and peroxidase-labeled streptavidin, the staining was developed by reaction with diaminobenzidine substrate-chromogen solution, followed by counterstaining with hematoxylin 7211 (Richard-Allan Scientific, Kalamazoo, MI, USA). In each experiment, a negative control was included in which the primary antibody was replaced by preimmune mouse IgG. The positive control used in this study was a colorectal adenocarcinoma known to overexpress EGFR.

The staining was interpreted according to Dako EGFR phamDx interpretation guide recommended for colorectal adenocarcinoma (http://www. dakocytomation.us/). That is, a tumor was recorded positive when $\geq 1 \%$ of the tumor cells exhibited any complete or incomplete circumferential membranous staining (with or without cytoplasmic staining) above background level. Cases with $<1 \%$ of the tumor cells stained were considered negative. Positive cases were further stratified based on staining intensity as $1+$ (weak), $2+$ (moderate), and $3+$ (strong).

The immunostaining was also analyzed for the staining extent. Positive cases were stratified as diffuse ( $>50 \%$ of the tumor cells stained), which was further divided into two subgroups (51-75\% and $>75 \%$ ), and focal $(<50 \%$ of the tumor cells stained), which was further divided into three subgroups (1-5, 6-25 and 26-50\%).

\section{Fluorescence In Situ Hybridization (FISH) and Data Analysis}

FISH analysis was performed on $5-\mu \mathrm{m}$ sections from representative paraffin blocks as previously described. $^{32}$ Paired commercial SpectrumGreenlabeled centromere enumerating probe 7 (CEP7; Vysis Inc., Downers Grove, IL, USA) and homebrew rhodamine-labeled EGFR (Human BAC library RPCI11 148P17, Washington University Human Genome Sequencing Center, St Louis, MO, USA) DNA probes were utilized for dosage determinations. Deparaffinization of the sections was carried out with two 10min immersions in Citrisolv, followed by three 3- 
min immersions in isopropanol. The slides were next rinsed in running water for $5 \mathrm{~min}$, followed by distilled water for $3 \mathrm{~min}$. Target retrieval was achieved by immersing the slides in a plastic Coplin jar filled with citrate buffer ( $\mathrm{pH}$ 6.0) placed in a steam cooker for $20 \mathrm{~min}$, then slowly cooled to room temperature. The slides were then rinsed in running water for $5 \mathrm{~min}$, followed by distilled water for 3 min. This was followed by $0.4 \%$ pepsin (P-7012; Sigma-Aldrich, St Louis, MO, USA) digestion for $15 \mathrm{~min}$ at $37^{\circ} \mathrm{C}$, and then a rinse in $2 \times$ standard saline citrate (SSC) on a rotator for $5 \mathrm{~min}$. Slides were then air dried. FISH probes were diluted from stock solutions with $\mathrm{tDenHyb}^{\mathrm{TM}}$ hybridization buffer (Insitus Biotechnologies, Albuquerque, NM, USA) to a concentration of 1:25 and dispensed at $10 \mu \mathrm{l}$ per slide. Slides were coverslipped with target and probe DNA subsequently codenaturated for $13 \mathrm{~min}$ in a light-shielded slide moat preheated to $90^{\circ} \mathrm{C}$. The slides were removed and kept in darkness until the slide moat reached a temperature of $37^{\circ} \mathrm{C}$. Slides were then replaced into the slide moat, which was then used as a $37^{\circ} \mathrm{C}$ humidified chamber for overnight hybridization. The next day, slides were removed from the $37^{\circ} \mathrm{C}$ humidified chamber. Coverslips were removed and the slides were washed in $50 \%$ formamide/ $1 \times$ SSC solution and placed on a rotator for $5 \mathrm{~min}$. This was followed by two washes of SSC for $2 \mathrm{~min}$ each. Slides were removed and allowed to air dry. In all, $10 \mu \mathrm{l}$ of DAPI in Fluorgard (Insitus Biotechnologies) was applied to each of the slides, which were then coverslipped.

Green and red fluorescent signals were enumerated under an Olympus BX60 fluorescence microscope with appropriate filters (Olympus, Melville, NY, USA). For each hybridization, a minimum of 100 nonoverlapping nuclei were assessed for numbers of green and red signals. An interpretation of monosomy 7 was made when $>50 \%$ of the nuclei harbored only one green centromere signal. Polysomies or gains of chromosome 7 were defined by the presence of at least $10 \%$ nuclei with $>2$ signals. Specimens were considered amplified for EGFR when they demonstrated nuclei containing innumerable red signals or an EGFR:CEP7 ratio $>2$. Cases without any detectable alterations were considered disomic (ie, two copies of chromosome 7 and EGFR). FISH images were captured using a black and white, high-resolution COHU CCD camera, Z-stack motor and CytoVision ${ }^{\mathrm{TM}}$ basic workstation (Applied Imaging, Santa Clara, CA, USA), with sequential DAPI (1 level), FITC (10 levels), and rhodamine (10 levels) filter settings. The resulting images were reconstituted with blue, green, and red pseudocolors using CytoVision ${ }^{\mathrm{TM}}$ software. A nonneoplastic brain specimen and a glioblastoma specimen with known EGFR amplification served as negative and positive controls, respectively.

\section{Statistical Analysis}

Statistical analysis was performed using the Statistica software for windows (StatSoft Inc., Tulsa, OK, USA). A $P$-value of $<0.05$, as determined by twotailed Fisher's exact test or the $\chi^{2}$ test with Yates continuity correction, was considered statistically significant.

\section{Results}

\section{Clinicopathologic Features of Squamous Cell Carcinomas of the Anal Canal}

The patients with anal canal squamous cell carcinomas ranged in age from 35 to 88 years (mean, 62.9 years; median, 65 years). Thirteen patients were male and 25 were female, with a male-to-female ratio of 1:1.9. At the time of diagnosis, 28 tumors were stage I ( $74 \%)$, seven stage II, two stage III, and one stage IV. Histologically, 26 tumors $(68 \%)$ were nonkeratinizing with basaloid features (Figure 1a), and the remaining 12 were keratinizing (Figure 1b).
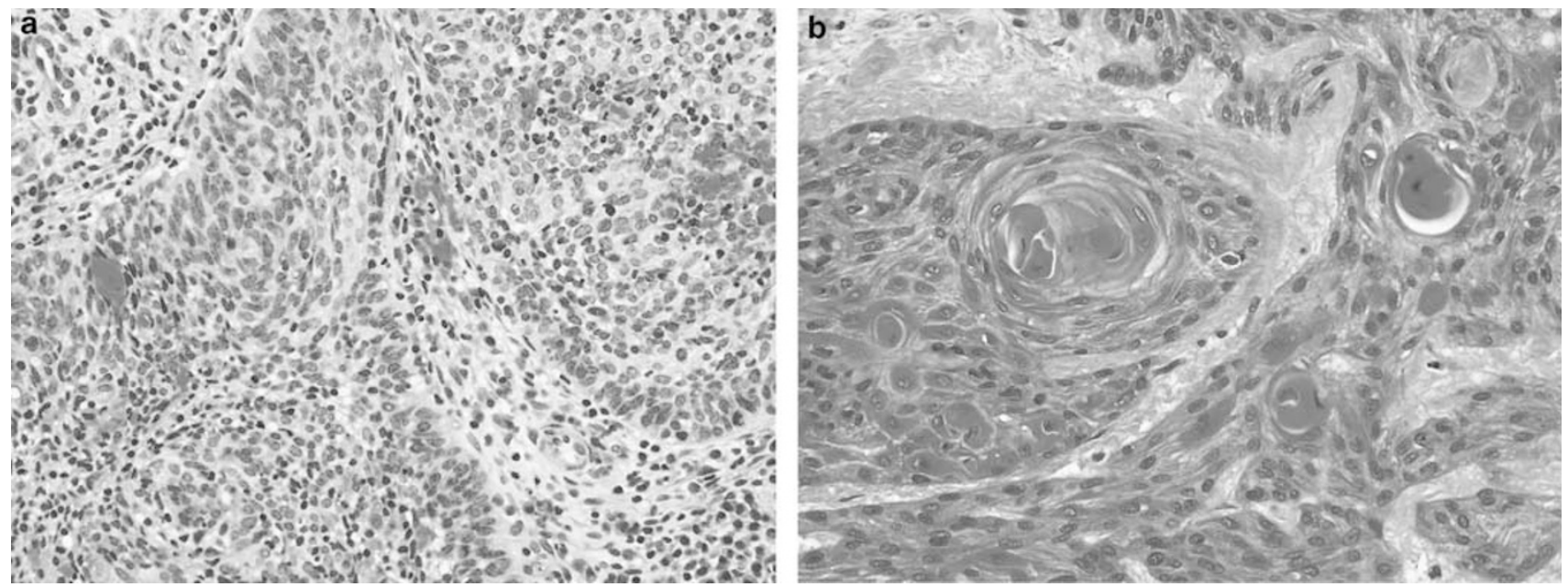

Figure 1 Squamous cell carcinoma of the anal canal, nonkeratinizing (a) and keratinizing (b) subtypes (original magnification $\times 400$ ). 
An association with human papillomavirus has been previously assessed in 25 cases, all of which were found to harbor high-risk human papillomavirus DNA, mostly type $16 .^{29}$

Clinical follow-up data were available in 18 cases. All of these patients were treated with synchronous chemoradiation therapies, with the chemotherapeutic regimens consisting of fluorouracil plus mitomycin or cisplatin. The mean follow-up time for these patients was 22.6 months from the initial diagnosis (range: 2-56 months). At the last followup, $11(61 \%)$ patients were in complete remission, two were alive with the disease, and three died of anal cancer within 6 months. Two cases initially responded to chemoradiation but recurred at 8 and 39 months, respectively, after the initial diagnosis. These two cases were subsequently managed with surgical excision.

\section{Expression of EGFR in Squamous Cell Carcinomas of the Anal Canal}

Table 1 summarizes the immunohistochemical findings and shows that EGFR immunoreactivity

Table 1 Summary of EGFR expression in squamous cell carcinomas of the anal canal

\begin{tabular}{lccccr}
\hline Immunoreactivity & \multicolumn{5}{c}{ No. (\%) of cases } \\
\cline { 2 - 6 } & - & $1+$ & $2+$ & $3+$ & Total \\
\hline$<5 \%$ & $17(45)$ & $2(5)$ & 0 & 0 & $19(50)$ \\
$5-25 \%$ & 0 & $4(11)$ & $2(5)$ & $1(3)$ & $7(18)$ \\
$26-50 \%$ & 0 & $1(3)$ & $1(3)$ & $2(5)$ & $4(11)$ \\
$51-75 \%$ & 0 & $1(3)$ & $1(3)$ & $2(5)$ & $4(11)$ \\
$>75 \%$ & 0 & 0 & 0 & $4(11)$ & $4(11)$ \\
Total & $17(45)$ & $8(21)$ & $4(11)$ & $9(24)$ & 38 \\
\hline
\end{tabular}

The $\%$ denotes the percentage of tumor cells positively stained. - , negative immunostaining; + , positive immunostaining. was detected in 21 of $38(55 \%)$ tumors. Among them, $13(62 \%)$ cases exhibited a moderate $(2+)$ or strong $(3+)$ staining intensity (Figure 2a). The staining was diffuse in eight $(38 \%)$ tumors, and focal in the remaining cases. In only two cases, both scored $1+$, the immunoreactivity was observed in $<5 \%$ of the tumor cells (Figure $2 b$ ).

Table 2 further shows that EGFR expression in anal canal squamous cell carcinomas was unrelated to tumor stage or differentiation status. In addition, the duration of block storage time had no effect on the immunohistochemical detectability of EGFR protein in tumor cells. Among the three cases resulting in patients' death, EGFR staining was diffuse $3+$ in one, focal $3+$ in one, and negative in one. EGFR staining in the two cases with recurrent disease was diffuse $3+$ and completely negative, respectively.

\section{Analysis of EGFR Gene Copy Numbers in Squamous Cell Carcinomas of the Anal Canal}

FISH results were noninterpretable in four $(11 \%)$ cases due to weak signals and these cases were thus excluded from further analysis. Of the remaining 34 cases, none showed EGFR gene amplification. Balanced disomy 7 (two copies) was detected in 22 (65\%) tumors (Figure 3a), polysomy 7 (chromosomal gain) in $11(32 \%)$ tumors (Figure $3 \mathrm{~b})$, and monosomy 7 (chromosomal loss) in one $(3 \%)$ tumor. Increased gene copy numbers due to polysomy 7 appeared to occur more frequently in keratinizing tumors $(55 \%)$ than in nonkeratinizing variants $(22 \%)$, whereas balanced disomy 7 appeared to be more common in nonkeratinizing tumors (74 vs $46 \%$ ). These differences, however, did not reach a statistical significance $(P=0.1143$ and 0.1377 , respectively). In addition, the distribution of different FISH patterns did not appear to correlate with patient age, sex, or tumor stage.
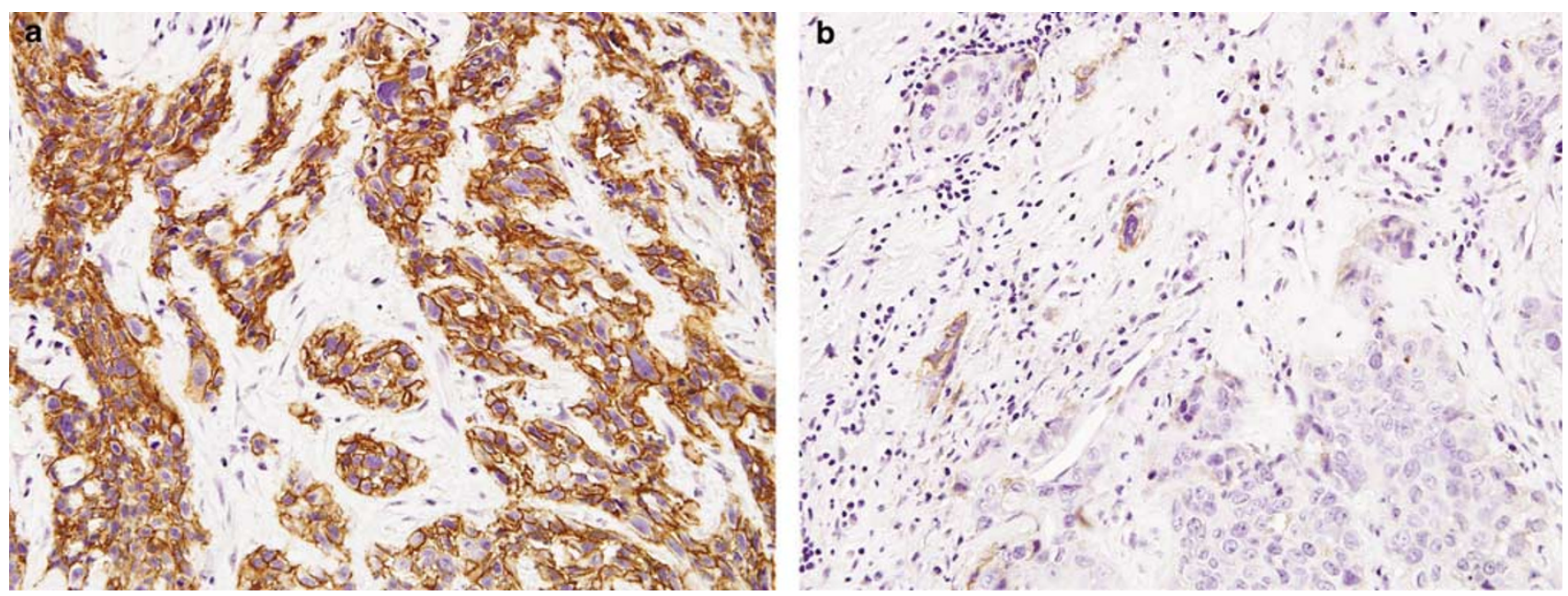

Figure 2 Expression of EGFR in squamous cell carcinoma of the anal canal, with diffuse and strong (a) and focal and weak (b) staining patterns (original magnification $\times 400$ ). 
Table 2 Correlation of EGFR expression with tumor stage, differentiation, and block storage time

\begin{tabular}{|c|c|c|c|c|c|c|}
\hline \multirow[t]{2}{*}{ Tumor } & \multicolumn{5}{|c|}{ EGFR expression } & \multirow[t]{2}{*}{$\mathrm{P}$-value } \\
\hline & - & $1+$ & $2+$ & $3+$ & No. (\%) positive & \\
\hline \multicolumn{7}{|l|}{ Stage } \\
\hline $\mathrm{I}(n=27)$ & 11 & 6 & 4 & 6 & $16(59)$ & $0.4910^{\mathrm{a}}$ \\
\hline II $(n=8)$ & 4 & 2 & 0 & 2 & $4(50)$ & \\
\hline III $(n=2)$ & 1 & 0 & 0 & 1 & $1(100)$ & \\
\hline IV $(n=1)$ & 1 & 0 & 0 & 0 & 0 & \\
\hline \multicolumn{7}{|l|}{ Differentiation } \\
\hline Keratinizing $(n=12)$ & 6 & 3 & 2 & 1 & $6(50)$ & 0.6618 \\
\hline Nonkeratinizing $(n=26)$ & 11 & 5 & 2 & 8 & $15(58)$ & \\
\hline \multicolumn{7}{|l|}{ Block storage time } \\
\hline$<2$ years $(n=10)$ & 6 & 0 & 1 & 3 & $4(40)$ & 0.2932 \\
\hline$>2$ years $(n=28)$ & 11 & 8 & 3 & 6 & $17(63)$ & \\
\hline
\end{tabular}

-, Negative immunostaining; +, positive immunostaining.

${ }^{\mathrm{a}}$ Based on a comparison between stage I tumors and stages II-IV as a group.
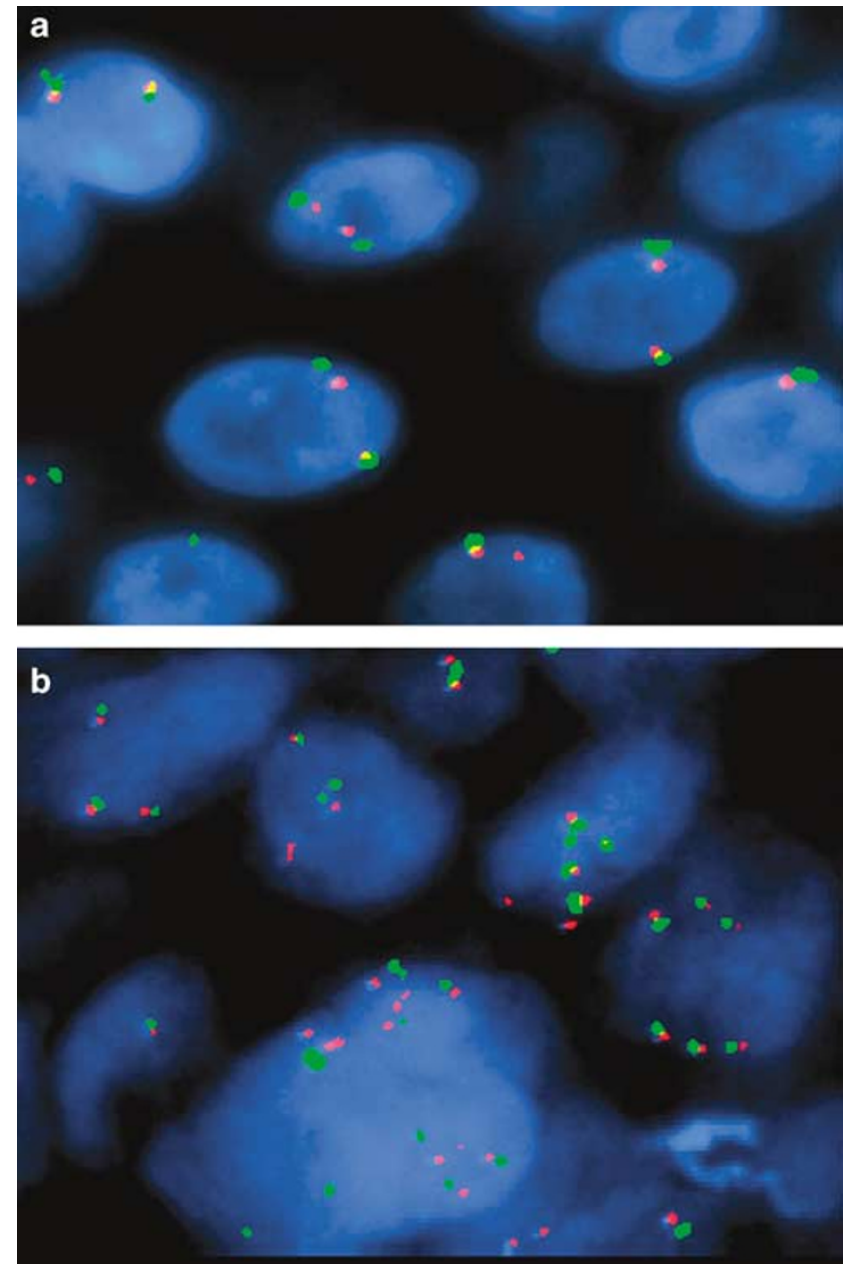

Figure 3 Balanced disomy 7 (a) and polysomy 7 (b) patterns in squamous cell carcinoma of the anal canal as demonstrated by FISH analysis. Centromere 7 signals are green and EGFR signals are red.

Table 3 shows the lack of correlation between EGFR protein expression and gene copy numbers. More specifically, polysomy 7 was detected in seven
Table 3 Correlation between chromosome 7 FISH patterns and EGFR protein expression

\begin{tabular}{lrcccc}
\hline Pattern & \multicolumn{5}{c}{ EGFR expression (no. of cases) } \\
\cline { 2 - 6 } & - & $1+$ & $2+$ & $3+$ & Total \\
\hline Disomy & 12 & 5 & 2 & 3 & 22 \\
Polysomy & 4 & 2 & 1 & 4 & 11 \\
Monosomy & 0 & 0 & 0 & 1 & 1 \\
Total & 16 & 7 & 3 & 8 & 34 \\
\hline
\end{tabular}

-, Negative immunostaining; +, positive immunostaining.

of 18 (39\%) tumors with positive EGFR immunostaining and four of $16(25 \%)$ cases showing negative EGFR immunoreactivity $(P=0.3876)$. Balanced disomy 7 was observed in 10 (56\%) cases that exhibited positive EGFR immunostaining and in 12 (75\%) cases that did not $(P=0.2363)$. The different FISH patterns also did not appear to correlate with the intensity of EGFR immunostaining. In fact, the one case with loss of chromosome 7 showed strong EGFR immunoreactivity $(3+)$.

\section{Discussion}

With the availability of effective anti-EGFR therapies for various solid malignancies, assessment of tumor EGFR status has become a frequent clinical question. In the current study, we demonstrate that more than one-half of the squamous cell carcinomas of the anal canal showed evidence of EGFR expression by immunohistochemistry. However, FISH analysis showed that this was not the result of either gene amplification or increased gene copy numbers due to polysomy 7 (these results have been presented in abstract forms at the 94th and 95th annual meetings of the United States and Canadian Academy of Pathology $y^{33,34}$ ). 
Of interest, our data differs significantly from those recently reported by Lê et al. ${ }^{35}$ In their study, all $21(100 \%)$ biopsies of anal canal squamous cell carcinomas showed universal and strong EGFR expression. Since we employed the same monoclonal antibody (clone 31G7) obtained from the same company (Zymed) and used at similar dilution (1:100 in their study), the discrepancy may be explained by different antigen-retrieval protocols. In our study, antigen retrieval was accomplished by treatment for $5 \mathrm{~min}$ with a bacterial protease extracted from $S$. griseus, which consistently gave a clean background. However, treatment with 1\% pepsin for $15 \mathrm{~min}$ was used in the study by Lê et $a l .{ }^{35}$ We have repeated our immunostains twice using $1 \%$ pepsin digestion (for $15 \mathrm{~min}$ at $37^{\circ} \mathrm{C}$ ) at antibody dilations of 1:100 and 1:200. Indeed, 36 of $38(95 \%)$ cases were found to be positively stained, but the background staining was also unacceptably high, even at an antibody dilution of 1:200 (data not shown).

Concern over the potential effects of tissue storage time on immunohistochemical detectability of EGFR protein stems from the observations by Atkins et $a l^{36}$ that the quality and quantity of EGFR immunoreactivity is inversely correlated with storage time of unstained tissue sections. However, neither our data nor those of Lê et $a l^{35}$ (which used archived tissue samples obtained 5-10 years ago) showed any evidence for loss of EGFR immunoreactivity in older cases, indicating that the storage time does not appear to matter if tissue blocks (rather than unstained sections) are utilized.

The finding that EGFR overexpression in squamous cell carcinomas of the anal canal is not the result of gene amplification is interesting, but not surprising, since a number of prior solid malignancy studies have similarly failed to show any correlation between the two. ${ }^{37-39}$ Proposed alternative mechanisms for EGFR upregulation include activating mutations, increased coexpression of receptor ligands, decreased receptor turnover, and heterodimerization with other heterologous receptor systems such as HER2. ${ }^{40}$ One of the most common EGFR mutations, EGFRvIII, involves an in-frame deletion of exons $2-7$ with resultant loss of residues 6-273 in the extracellular domain, which leads to constitutive activation of the receptor and resistance to downregulation by endocytosis. ${ }^{41}$ This mutation is predominantly encountered in glioblastomas with high-level gene amplifications as well. EGFR signals may also be enhanced by increased levels of receptor ligands (such as EGF, TGF- $\alpha$, or amphiregulin). ${ }^{42}$ Coexpression of EGFR and one or more of its ligands may also result in activation of an autocrine mechanism leading to dysregulated EGFR action. Moreover, heterodimerization with or overexpression of HER2 may potentiate EGFR functioning by increasing EGF-binding affinity, stabilizing EGFR, promoting rapid recycling of EGFR back to the cell surface, and expanding the repertoire of receptor-associated substrates and signaling responses. ${ }^{43,44}$ Furthermore, EGFR can 'crosstalk' with additional heterologous receptors activated by a variety of stimuli to amplify its biological activities. ${ }^{40}$

In general, EGFR overexpression has been found to be associated with advanced tumor stage and poor prognosis in a number of human malignancies, such as carcinomas of the esophagus, ${ }^{6}$ stomach, ${ }^{45}$ colorectum, ${ }^{16,46}$ bladder, ${ }^{11}$ and breast. ${ }^{10}$ Although inconclusive, these observations underscore the potential benefit of anti-EGFR therapy for patients with advanced diseases. Preliminary clinical results indicate that the effectiveness of anti-EGFR agents increases if combined with standard cytotoxic regimes and/or radiation therapy. ${ }^{20}$ Under these circumstances, blockade of EGFR signaling could cause irreparable cancer cell damage leading to increased programmed cell death. This combined approach is not only more effective, but also less toxic and more tolerable than other conventional modalities such as high-dose chemotherapy. ${ }^{20,47}$ Although the question whether EGFR expression correlates with survival of the patients with anal canal squamous cell carcinoma is beyond the scope of our study due to insufficient follow-up data in more than half of the cases, we found no statistical difference in EGFR expression among tumors with different stages. Of course, this conclusion may not be entirely valid, given that only three (8\%) advanced stage cases were included (two stage III and one stage IV). Therefore, questions of prognosis and associations with stage should still be addressed in future studies. Nevertheless, a lack of clear prognostic significance for EGFR expression should not preclude patients from the potential benefits of anti-EGFR therapy.

\section{Acknowledgements}

We thank Ms Prosperidad Amargo and Ruma Banerjee for their excellent technical assistance with immunohistochemistry and FISH, respectively.

\section{References}

1 Herbst RS. Review of epidermal growth factor receptor biology. Int J Radiat Oncol Biol Phys 2004;59: 21-26.

2 Koretz K, Schlag P, Moller P. Expression of epidermal growth factor receptor in normal colorectal mucosa, adenoma, and carcinoma. Virchows Arch A Pathol Anat Histopathol 1990;416:343-349.

3 Steele RJ, Kelly P, Ellul B, et al. Epidermal growth factor receptor expression in colorectal cancer. $\mathrm{Br} \mathrm{J}$ Surg 1990;77:1352-1354.

4 Yasui W, Sumiyoshi H, Hata J, et al. Expression of epidermal growth factor in human gastric and colonic carcinomas. Cancer Res 1988;48:137-141. 
5 Pfeiffer A, Rothbauer E, Wiebecke B, et al. Increased epidermal growth factor receptors in gastric carcinomas. Gastroenterology 1990;98:961-967.

6 Itakura Y, Sasano H, Shiga C, et al. Epidermal growth factor receptor overexpression in esophageal carcinoma: an immunohistochemical study correlated with clinicopathologic findings and DNA amplification. Cancer 1994;74:795-804.

7 Hirsch FR, Scagliotti GV, Langer CJ, et al. Epidermal Growth factor family of receptors in preneoplasia and lung cancer: perspectives for targeted therapies. Lung Cancer 2003;41:S29-S42.

8 Rusch V, Klimstra D, Venkatraman E, et al. Overexpression of the epidermal growth factor receptor and its ligand transforming growth factor alpha is frequent in resectable non-small cell lung cancer but does not predict tumor progression. Clin Cancer Res 1997;3: $515-522$.

9 Xiong HQ, Rosenberg A, LoBuglio A, et al. Cetuximab, a monoclonal antibody targeting the epidermal growth factor receptor, in combination with gemcitabine for advanced pancreatic cancer: a multicenter phase II trial. J Clin Oncol 2004;22:2610-2616.

10 Sainsbury JR, Farndon JR, Sherbet GV, et al. Epidermal-growth-factor receptors and oestrogen receptors in human breast cancer. Lancet 1985;1:364-366.

11 Neal DE, Marsh C, Bennett MK, et al. Epidermalgrowth-factor receptors in human bladder cancer: comparison of invasive and superficial tumours. Lancet 1985;1:366-368.

12 Sargent ER, Gomella LG, Belldegrun A, et al. Epidermal growth factor receptor gene expression in normal human kidney and renal cell carcinoma. J Urol 1989;142:1364-1368.

13 Ford AC, Grandis JR. Targeting epidermal growth factor receptor in head and neck cancer. Head Neck 2003;25:67-73.

14 Sporn MB, Roberts AB. Autocrine growth factors and cancer. Nature 1985;313:745-747.

15 Calvo E, Rowinsky EK. Clinical experience with monoclonal antibodies to epidermal growth factor receptor. Curr Oncol Rep 2005;7:96-103.

16 Kopp R, Rothbauer E, Mueller E, et al. Reduced survival of rectal cancer patients with increased tumor epidermal growth factor receptor levels. Dis Colon Rectum 2003;46:1391-1399.

17 El-Rayes BF, LoRusso PM. Targeting the epidermal growth factor receptor. Br J Cancer 2004;91:418-424.

18 Hinoda Y, Sasaki S, Ishida T, et al. Monoclonal antibodies as effective therapeutic agents for solid tumors. Cancer Sci 2004;95:621-625.

19 Ross JS, Schenkein DP, Pietrusko R, et al. Targeted therapies for cancer 2004. Am J Clin Pathol 2004; 122:598-609.

20 Ciardiello F, Tortora G. A novel approach in the treatment of cancer: targeting the epidermal growth factor receptor. Clin Cancer Res 2001;7: 2958-2970.

21 Burtness B, Goldwasser MA, Flood W, et al. Phase III randomized trial of cisplatin plus placebo compared with cisplatin plus cetuximab in metastatic/recurrent head and neck cancer: an Eastern Cooperative Oncology Group study. J Clin Oncol 2005;23: 8646-8654.

22 Veronese ML, O’Dwyer PJ. Monoclonal antibodies in the treatment of colorectal cancer. Eur J Cancer 2004;40:1292-1301.
23 Burtness B. Cetuximab and cisplatin for chemotherapy-refractory squamous cell cancer of the head and neck. J Clin Oncol 2005;23:5440-5442.

24 Cunningham D, Humblet Y, Siena S, et al. Cetuximab monotherapy and cetuximab plus irinotecan in irinotecan-refractory metastatic colorectal cancer. N Engl J Med 2004;351:337-345.

25 Chung KY, Shia J, Kemeny NE, et al. Cetuximab shows activity in colorectal cancer patients with tumors that do not express the epidermal growth factor receptor by immunohistochemistry. J Clin Oncol 2005;23:18031810.

26 Meyerhardt JA, Mayer RJ. Systemic therapy for colorectal cancer. N Engl J Med 2005;352:476-487.

27 Frisch M. On the etiology of anal squamous carcinoma. Dan Med Bull 2002;49:194-209.

28 Licitra L, Spinazzé S, Doci R, et al. Cancer of the anal region. Crit Rev Oncol Hematol 2002;43:77-92.

29 Lu DW, El-Mofty SK, Wang HL. Expression of p16, Rb, and p53 proteins in squamous cell carcinomas of the anorectal region harboring human papillomavirus DNA. Mod Pathol 2003;16:692-699.

30 Wang HL. Role of immunohistochemical expression of p53, Rb, and p16 proteins in anal squamous cell carcinoma. In: Hayat MA (ed). Handbook of Immunohistochemistry and In Situ Hybridization of Human Carcinomas. Volume 2: Molecular Pathology, Colorectal Carcinoma, and Prostate Carcinoma. Elsevier Academic Press: Burlington, MA, 2005, pp 267-275.

31 Quan SH. Anal cancers: squamous and melanoma. Cancer 1992;70:1384-1389.

32 Perry A, Aldape KD, George DH, et al. Small cell astrocytoma: an aggressive variant that is clinicopathologically and genetically distinct from anaplastic oligodendroglioma. Cancer 2004;101:2318-2326.

33 Alvarez G, Tan BR, Wang HL. Expression of epidermal growth factor receptor in squamous cell carcinomas of the anal canal. Mod Pathol 2005;18(Suppl 1):96A (Abstract).

34 Alvarez G, Perry A, Wang HL. Expression of epidermal growth factor receptor in squamous cell carcinomas of the anal canal is independent of gene amplification. Mod Pathol 2006;19(Suppl 1):101A (Abstract).

35 Lê LH, Chetty R, Moore MJ. Epidermal growth factor receptor expression in anal canal carcinoma. Am J Clin Pathol 2005;124:20-23.

36 Atkins D, Reiffen KA, Tegtmeier CL, et al. Immunohistochemical detection of EGFR in paraffinembedded tumor tissues: variation in staining intensity due to choice of fixative and storage time of tissue sections. J Histochem Cytochem 2004;52: 893-901.

37 al-Kasspooles $\mathrm{M}$, Moore $\mathrm{JH}$, Orringer $\mathrm{MB}$, et al. Amplification and over-expression of the EGFR and erbB-2 genes in human esophageal adenocarcinomas. Int J Cancer 1993;54:213-219.

38 Berger MS, Gullick WJ, Greenfield C, et al. Epidermal growth factor receptors in lung tumors. J Pathol 1987;152:297-307.

39 Kearsley JH, Leonard JH, Walsh MD, et al. A comparison of epidermal growth factor receptor (EGFR) and c-erbB-2 oncogene expression in head and neck squamous cell carcinomas. Pathology 1991;23: 189-194.

40 Arteaga C. Epidermal growth factor receptor dependence in human tumors: more than just expression? Oncologist 2002;7:31-39. 
41 Kuan CT, Wikstrand CJ, Bigner DD. EGF mutant receptor vIII as a molecular target in cancer therapy. Endocr Relat Cancer 2001;8:83-96.

42 Gorgoulis V, Aninos D, Mikou P, et al. Expression of EGF, TGF- $\alpha$ and EGFR in squamous cell lung carcinomas. Anticancer Res 1992;12:1183-1187.

43 Karunagaran D, Tzahar E, Beerli RR, et al. ErbB-2 is a common auxiliary subunit of NDF and EGF receptors: implications for breast cancer. EMBO J 1996;15:254-264.

44 Worthylake R, Opresko LK, Wiley HS. ErbB-2 amplification inhibits down-regulation and induces constitutive activation of both ErbB-2 and epidermal growth factor receptors. J Biol Chem 1999;274:8865-8874.
45 Kopp R, Ruge M, Rothbauer E, et al. Impact of epidermal growth factor (EGF) radioreceptor analysis on long-term survival of gastric cancer patients. Anticancer Res 2002;22:1161-1167.

46 Goldstein NS, Armin M. Epidermal growth factor receptor immunohistochemical reactivity in patients with American Joint Committee on Cancer stage IV colon adenocarcinoma: implications for a standardized scoring system. Cancer 2001;92: 1331-1346.

47 Mendelsohn J, Fan Z. Epidermal growth factor receptor family and chemosensitization. J Natl Cancer Inst 1997;89:341-343. 